was present in both genera. Ericiolacerta represents an early stage in the transition from a sectorial to a pounding or crushing dentition, but it is doubted whether a true grinding action was present in Bauria.

\section{Biological Objects in Plastic}

IT has become increasingly the custom in Museums to embed various biological specimens in plastic and thus preserve colour and shape far better than by the older methods. Messrs. G. Notini and Sigrid V. Wettstein have just published in the Bulletin of the Royal School of Forestry, Stockholm (Kungl. Skogshögskolans Skrifter. Nr. 36: "Embedding Biological Objects in Plastic". Pp. $34 . \quad$ Stockholm: Emil Kihlströms Tryckeri AB., 1961) a very useful paper with full descriptive notes of the technical work involved. The authors have carried out a prolonged investigation on this subject, and the paper includes details not only of the preparation of objects for embedding but also of the actual embedding procedure and the details as applied to the following types of objects: Lepidoptera, Coleoptera, Hymenoptera, Diptera, spiders, fishes, crustaceans, centipedes, reptiles, small mammals and anatomical preparations. Also included is a useful list of references to previous work.

\section{Semiconductors and Transistors}

THE Special Subject List No. 36 of the Library Association, entitled Semiconductors and Transistors, has been compiled by E. H. C. Driver, librarian of the College of Advanced Technology, Birmingham (Pp. 19. 6s.; Library Association members, 4s. 6d. London: The Library Association, 1961). It contains a preface by Prof. R. A. Smith, University of Sheffield, and represents an adequate, but obviously not complete, bibliography of the large and rapidly growing literature on the subject. Books published earlier than 1955 have been included only if especially useful and most of the entries refer to the years 1959-62. The 63 entries, apart from a separate list of periodicals, are grouped under the headings: guides to the literature; abstracts; surveys and reviews; definitions, standards; and a select book list divided into five sections. Popular paper-backs on transistor circuits for the home constructor have been excluded. No prices of books are given and the entries have been limited to texts in English. The List, which concludes with an excellent index, should be most helpful to those searching the literature or wishing to commence a small collection of books on the subject of semiconductors.

\section{The National Meteorological Library}

Now that the Meteorological Office is fully established in its new building at Bracknell, Berkshire, its library is properly housed in suitable accommodation, and, except for its geographical location, is fully accessible. Some of the material stored is on open shelves, and there are large stock rooms to which readers are not normally admitted. The reading room is largo and pleasant, with card index and loan facilities readily available. The indexing is thorough, and in addition to the usual author-index there is a comprehensive subject-index which is based on the Universal Decimal Classification. In this the author and title of every paper held on each subject are listed in chronological order. A considerable number of translations of foreign literature are held, and this store is being continually augmented. There is a room set aside for viewing micro-films and microcards. These valuable facilities are available to the public for bona fide purposes.

\section{Testing Ferrous Metals for Corrosion Resistance}

A USEFUL booklet has been prepared by Mr. K. A. Chandler for the Methods of Testing (Corrosion) Sub-Committee of the British Iron and Steel Research Association (Testing Ferrous Metals for Corrosion Resistance. Pp. 27 (MG/BF/19/61). London: British Iron and Steel Research Association, 1962. 3s. 6d.), In this he discusses a number of simple corrosiontesting procedures which require neither specialized experience nor complex equipment. Designed, in the main, to meet the needs of small and medium-sized furms, it starts with a general introduction and then goes on to consider the choice of test and the preparation of specimens. Laboratory tests are dealt with in the longest chapter and followed by field tests and service trials. The final chapter is a very helpful account of the assessment of the results in terms of practical behaviour.

\section{Utilization of Activated Sludge}

THE activated sludge process is an aerobic and rapid method of sewage purification, which yields a sludge that settles down quickly, leaving a clear, well-oxidized effluent. These changes are essentially brought about by micro-organisms which thrive in sewage under aerobic conditions. Since the early days of the development of the process, attempts have been made to utilize activated sludge for agricultural purposes. In recent years the possibility of utilizing sludge more directly as a feed supplement for animals has been investigated. An article by S. Sathyanarayana Rao and S. C. Pillai, of the Depart. ment of Biochemistry, Indian Institute of Science, Bangalore, gives a brief account of the studies, particularly on vitamin $B_{12}$, in activated sludge and on the utilization of the sludge as a feed supplement for farm animals, such as chicks and pigs (J. Sci. Indust. Res. A. General. 21A. No. $1 ; 1962$ ). The work was started soon after the discovery of vitamin $B_{12}$ and recognition of its importance in the nutrition of man and animals. There is already some evidence to indicate the value of activated sludge as a feed supplement. In addition to certain nutrients, activated sludge also may contain other substances as a result of intense microbial activity. Activated sludge concentrates coenzyme $Q^{72}$, and it may be considered as a source of coenzyme $Q$ in view of the recent attempt to produce it by bacterial fermentation of cortain synthetic media.

\section{The Royal Commission for the Exhibition of 1851 : Awards}

THE following awards for 1962 have been announced: Senior Studentships : K. Bearpark (University of Oxford) for research in physics at Oxford; J. F. P. Hudson (University of Cambridge) for research in mathematics at Cambridge; D. I. John (University College, Swansea, and Imperial College of Science and Technology) for rescarch in organic chemistry at Imperial College; J. R. Waldram (University of Cambridge) for research in physics at Cambridge. Overseas Scholarships: (1) Canada. M. C. L. Gerry (University of British Columbia) for research in physical chemistry at Cambridge; $P$. Copper (University of Saskatchewan) for research in geology at Tubingen; J. J. Simpson (University of Toronto) for research in nuclear physics at Oxford; (2) Austratia, J. D. Cotton (University of Melbourne) for research in inorganic chemistry at Cambridge; J. L. Black (University of Melbourne) for research in nuclear physics at Oxford; B. D. Jones (University 